\title{
Functional reconstitution, membrane targeting, genomic structure, and chromosomal localization of a human urate transporter
}

\author{
Michael S. Lipkowitz, ${ }^{1}$ Edgar Leal-Pinto, ${ }^{1}$ Joshua Z. Rappoport, ${ }^{1}$ Vesna Najfeld, ${ }^{2}$ \\ and Ruth G. Abramson ${ }^{1}$ \\ ${ }^{1}$ Division of Nephrology, and \\ ${ }^{2}$ Tumor Cytogenetics, Department of Medicine, Mount Sinai School of Medicine, New York, New York, USA \\ Address correspondence to: Michael S. Lipkowitz, Division of Nephrology, Department of Medicine, \\ Mount Sinai School of Medicine, One Gustave L. Levy Place, Box 1243, New York, New York 10029, USA. \\ Phone: (212) 241-2264; Fax: (212) 987-0389; E-mail: mike.lipkowitz@mssm.edu.
}

Received for publication February 8, 2001, and accepted in revised form March 20, 2001.

\begin{abstract}
Elevated serum levels of uric acid have been associated with an increased risk for gout, hypertension, cardiovascular disease, and renal failure. The molecular mechanisms for the diminished excretion of urate in these disorders, however, remain poorly understood. Human galectin 9, which is highly homologous to the rat urate transporter rUAT, has been reported to be a secreted or cytosolic protein. We provide data that galectin 9 is hUAT, the first identified human urate transporter. hUAT is a highly selective urate ion channel when inserted in lipid bilayers. When expressed in renal epithelial cells it is an integral plasma membrane protein with at least two transmembrane domains. The gene for hUAT consists of 11 exons and is mapped to chromosome 17; a highly homologous gene, bUAT2, maps to a nearby region of chromosome 17 and is also likely to be a urate transporter. hUAT is expressed in a wide variety of tissues and is present in at least three isoforms; hUAT2 is less widely expressed at severalfold lower levels than hUAT. Further knowledge about the functions of hUAT, its isoforms, and hUAT2, as well as mutational analysis of $b U A T 1$ and $b U A T 2$ in individuals or families with hyperuricemia, should significantly improve our understanding of the molecular mechanisms of urate homeostasis.
\end{abstract}

J. Clin. Invest. 107:1103-1115 (2001).

\section{Introduction}

Urate is produced within all mammalian cells as the product of purine degradation (1); however, little is known as yet about the pathway for urate efflux from cells. Humans, unlike other species (2-4), have lost the ability to oxidize urate to allantoin with the enzyme uricase as a result of loss of function mutations in the uricase gene $(5,6)$. Consequently, plasma urate is many fold higher in humans than in species with uricase, and maintenance of urate homeostasis is critically dependent on renal (7), and to a lesser extent intestinal urate, elimination $(8,9)$. Since there is mounting evidence that hyperuricemia is associated with pathogenic states in humans, including hypertension, gout, renal failure, and cardiovascular disease, our knowledge regarding urate transport in renal and intestinal epithelial cells, as well as in nonpolarized cells in which urate is produced, may become increasingly relevant.

Studies by our group and others have demonstrated two mechanisms for urate transport in the kidney, a voltage-sensitive urate transporter (10-13) and a urate/anion exchanger (14-19). Recently we cloned a cDNA from rat kidney that is likely the molecular representation of the voltage-sensitive urate transporter (20). This conclusion is based on the fact that recombinant protein prepared from the rat cDNA functions as a highly selective urate channel with many charac- teristics comparable to the rat electrogenic urate transporter $(20,21)$. Of note, this cloned urate transporter/channel protein, designated rUAT, exhibits a high degree of homology to the galectin family of proteins (20) and is $99 \%$ identical to the subsequently reported rat galectin $9(22,23)$. More recently, the human homologue of rat galectin 9 , with $73 \%$ identity to rUAT, has also been reported (24-26). Similar to other members of the galectin family (27-35), human galectin $9(24)$ and ecalectin $(25,26)$, a protein that is probably identical to galectin 9 , are reported to be soluble secreted proteins, not transmembrane transport proteins. Human galectin 9 is reported to participate in cellular interactions of the immune system (24) whereas ecalectin is considered to be a specific eosinophil chemoattractant $(25,26)$.

Despite the diverse functions assigned to rUAT and galectin 9/ecalectin, the very high degree of homology between rUAT and human galectin 9 prompted us to evaluate the possibility that galectin 9 is the human homologue of the rat voltage-sensitive urate transporter. The studies reported in this paper were therefore designed to determine whether recombinant human galectin 9 (hereafter referred to as hUAT) can, like rUAT, act as a selective urate channel in an artificial lipid bilayer system, to assess whether hUAT is an integral membrane protein that spans the plasma membrane in kid- 
ney cells, to examine the tissue distribution of hUAT, and to determine the chromosomal localization and genomic structure of WUAT. These studies indicate that hUAT functions as a very selective urate channel when inserted in planar lipid bilayers, that hUAT localizes to plasma membranes where it resides as an integral membrane protein with at least two membrane-spanning domains when expressed in mammalian kidney cells, and that the mRNA for hUAT is expressed in a wide variety of human tissues. These studies demonstrate that the bUAT gene maps to the short arm of human chromosome 17, that this gene contains 11 exons and is expressed as three isoforms, and that the bUAT gene is $96 \%$ identical to a novel gene, $b U A T 2$, that exhibits a very different pattern of expression.

\section{Methods}

Preparation of RNA and DNA. Blood was obtained from five human subjects who agreed to participate in a study of genes related to hypertension and signed Institutional Review Board-approved consent documents, and from an author. PBMCs were isolated using a Ficoll gradient (Ficoll-Paque; Amersham Pharmacia Biotech, Piscataway, New Jersey, USA). Total RNA was prepared from the PBMCs using Tri-Reagent (MRC Inc., Cincinnati, Ohio, USA) according to the manufacturer's directions. Messenger RNA was then isolated using the OligoTex oligo-dT resin and spin columns (QIAGEN Inc., Valencia, California, USA). Genomic DNA was prepared from an additional 1-ml aliquot of blood using the PUREGENE Kit (Gentra Systems, Minneapolis, Minnesota, USA).

Preparation of recombinant bUAT protein. Total RNA (2 $\mu \mathrm{g})$ prepared from blood of a normal donor was reverse transcribed to full-length cDNA using Superscript II reverse transcriptase (Roche Molecular Biochemicals, Indianapolis, Indiana, USA) and an oligo- $\mathrm{dT}_{15}$ primer.
The PCR was then performed using PfuTurbo DNA polymerase (Stratagene, La Jolla, California, USA) to amplify the coding region of galectin 9 (Genbank accession number Z49107) using primers containing the start and stop codons (Table 1, first primer pair). These and all other primers were purchased from Genosys Biotechnologies, Inc. (The Woodlands, Texas). PCR products were analyzed by electrophoresis, purified using a gel extraction kit (QIAGEN Inc.), and subcloned into pBluescript SK(-) (Stratagene). DNA from plasmid minipreps was evaluated by digestion with appropriate restriction enzymes, and the identity of hUAT constructs to galectin 9 was verified by sequencing. Large quantities of plasmid DNA were then produced using a maxiprep kit (QIAGEN Inc.). The insert was then excised from pBluescript and inserted in frame into the prokaryotic expression vector pRSET A (Invitrogen Corp., Carlsbad, California, USA), generating a hUAT-6 histidine fusion construct. This allowed purification of recombinant protein on a nickel-chelating resin, nickelnitrilotriacetic acid (Ni-NTA) (QIAGEN Inc.). The resulting plasmid, pRSETA-hUAT, was employed to transform BL21(DE3)pLysE bacteria (Novagen, Madison, Wisconsin, USA) for expression of recombinant hUAT protein. For the last 4 hours of culture, transformed bacteria were grown in the presence of isopropyl-1-thio- $\beta$-D-galactopyranoside (IPTG) $(0.4 \mathrm{mM})$, then pelleted by centrifugation and stored at $-70^{\circ} \mathrm{C}$.

The recombinant hUAT protein was isolated using a modification of the single-step purification/solubilization method (36). Bacteria were lysed in $6 \mathrm{M}$ guanidine, $20 \mathrm{mM}$ Tris-Cl, $500 \mathrm{mM} \mathrm{NaCl}, 20 \mathrm{mM}$ imidazole, $1 \mathrm{mM} \beta$-mercaptoethanol, and $0.1 \%$ Triton $\mathrm{X}-100$ at $\mathrm{pH}$ 7.9, added to Ni-NTA agarose pre-equilibrated in the same buffer, then mixed by rotation for 30 minutes. The Ni-NTA agarose was washed twice by centrifugation and resuspension in the same lysis buffer, then

Table 1

Primers and oligonucleotides for expression/fusion constructs and PCR

\begin{tabular}{|c|c|c|}
\hline PCR product & & Oligonucleotide sequence \\
\hline $5^{\prime}$ Xhol-hUAT-HindIII & $\begin{array}{l}(\mathrm{S}) \\
(\mathrm{AS})\end{array}$ & $\begin{array}{l}5^{\prime} \text { GC } \text { CTC GAG ATG GCC TTC AGC GGT TCC CAG } \\
5^{\prime} \text { GC } \text { AAG CTT CTA TGT CTG CAC ATG GGT CAG C }\end{array}$ \\
\hline 5' BamHI-hUAT-HindIII & $\begin{array}{l}(\mathrm{S}) \\
(\mathrm{AS})\end{array}$ & $\begin{array}{l}5^{\prime} \text { GC } \text { GGA TCC ATG GCC TTC AGC GGT TCC CAG } \\
5^{\prime} \text { GC } \text { AAG CTT CTA TGT CTG CAC ATG GGT CAG C }\end{array}$ \\
\hline $5^{\prime}$ Xhol-hUAT-Kpnl & $\begin{array}{l}(\mathrm{S}) \\
(\mathrm{AS})\end{array}$ & $\begin{array}{l}5^{\prime} \text { GC } \\
5^{\prime} \text { GTC GAG ATG GCA ACC TGT CTG } \text { CAC ATG GGT CAG CTG C }\end{array}$ \\
\hline $5^{\prime}$ Xhol-EGFP-BamHI & $\begin{array}{l}(\mathrm{S}) \\
(\mathrm{AS})\end{array}$ & $\begin{array}{l}5^{\prime} \text { GC } \\
\text { 5TC GAG ATG GTG AGC AAG GGC GAG GAG C } \\
\text { 5' GA TCC CTT GTA CAG CTC GTC CAT GCC }\end{array}$ \\
\hline $5^{\prime}$ KpnI-EGFP-HindIII & $\begin{array}{l}(\mathrm{S}) \\
(\mathrm{AS})\end{array}$ & 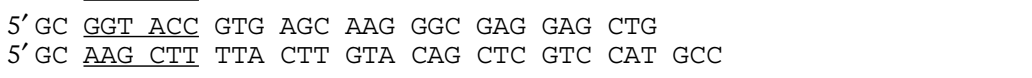 \\
\hline $5^{\prime}$ Xhol-FLAG-BamHI & $\begin{array}{l}(\mathrm{S}) \\
(\mathrm{AS})\end{array}$ & 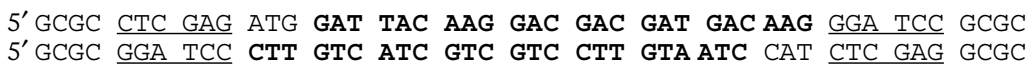 \\
\hline $5^{\prime}$ KpnI-FLAG-HindIII & $\begin{array}{l}(\mathrm{S}) \\
(\mathrm{AS})\end{array}$ & 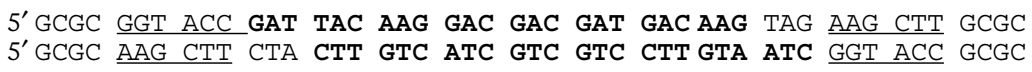 \\
\hline hUAT-specific & $\begin{array}{l}(\mathrm{S}) \\
(\mathrm{AS})\end{array}$ & $\begin{array}{l}\text { 5' ACACAGTGCAGAGTGCCT } \\
5^{\prime} \text { CGTCAGCTGCCTTCTCCG }\end{array}$ \\
\hline hUAT2-specific & $\begin{array}{l}(\mathrm{S}) \\
(\mathrm{AS})\end{array}$ & $\begin{array}{l}5^{\prime} \text { ACACGGTGCAGAGTGCCT } \\
5^{\prime} \text { AGTCAGCTGCCTTCTCGA }\end{array}$ \\
\hline
\end{tabular}

Restriction enzyme sites are underlined. The coding sequences of FLAG epitopes are in boldface. S, sense primer/oligonucleotide; AS, antisense primer/oligonucleotide. 
packed in a disposable column. The column was washed with $6 \mathrm{M}$ urea, $20 \mathrm{mM}$ Tris-Cl, $500 \mathrm{mM} \mathrm{NaCl}$, $20 \mathrm{mM}$ imidazole, $1 \mathrm{mM} \beta$-mercaptoethanol, $0.1 \%$ Triton $\mathrm{X}-100$, and complete protease inhibitor (Roche Molecular Biochemicals, Mannheim, Germany) at $\mathrm{pH}$ 7.9 , then washed with $20 \mathrm{mM}$ Tris- $\mathrm{Cl}, 150 \mathrm{mM} \mathrm{NaCl}$, $20 \mathrm{mM}$ imidazole, $1 \mathrm{mM} \beta$-mercaptoethanol, $0.1 \%$ Triton $\mathrm{X}-100$, and protease inhibitor at $\mathrm{pH}$ 7.9. Recombinant protein was subsequently eluted in 5 - $\mathrm{ml}$ aliquots of the same solution containing $50 \mathrm{mM}$ EDTA.

Western blot analysis. Aliquots $(20 \mu \mathrm{l})$ of eluates were dissolved in Laemmli buffer, electrophoretically resolved on $10 \%$ SDS-polyacrylamide gels, and transferred to a nitrocellulose filter (Bio-Rad Laboratories, Hercules, California, USA). Membranes were blocked overnight at $4^{\circ} \mathrm{C}$ in $5 \%$ powdered nonfat milk in PBS, washed six times in PBS-Tween-20, and then incubated for 1 hour at $25^{\circ} \mathrm{C}$ with either a primary affinity-purified polyclonal $\mathrm{Ab}$ to porcine uricase (37) or an $\mathrm{Ab}$ to the His-tag (Invitrogen Inc.) that was diluted 1:1000 or 1:15,000, respectively, in PBS with $2 \%$ BSA. After six washes at $25^{\circ} \mathrm{C}$ in PBS-Tween-20, the blots were incubated at $25^{\circ} \mathrm{C}$ with the appropriate peroxidase-labeled secondary $\mathrm{Ab}$ (Kirkegaard \& Perry Laboratories Inc., Gaithersburg, Maryland) that was diluted 1:5,000 in PBS with 5\% nonfat milk. For detection of hUAT, the membranes were incubated 1 hour with the secondary Ab; for the His-tag, incubation was for 30 minutes. Thereafter the membranes were washed six times in PBS-Tween-20 and then visualized by enhanced chemiluminescence (ECL) after exposure of the membranes to Hyperfilm (Amersham International, Amersham, United Kingdom).

Lipid bilayer studies. Ion channel activity was assayed in a lipid bilayer system as described previously $(20,21)$. Purified hUAT protein was sonicated with a 1:1 mixture of bovine phosphatidylserine (PS) and phosphatidylethanolamine (PE) (Avanti Polar Lipids Inc., Alabaster, Alabama, USA), suspended in $220 \mathrm{mM}$ $\mathrm{Cs}_{2} \mathrm{SO}_{4}, 10 \mathrm{mM}$ HEPES-NaOH, $\mathrm{pH}$ 7.4, and sonicated to form proteoliposomes. The two cups of the bilayer chamber, separated by a Teflon sheet containing a 50$\mu \mathrm{m}$ hole, were initially filled with $2.5 \mathrm{mM}$ urate, 220 $\mathrm{mM} \mathrm{Cs}_{2} \mathrm{SO}_{4}, 10 \mathrm{mM}$ HEPES-NaOH, $\mathrm{pH}$ 7.4. The lipid bilayer was formed by painting PS/PE dissolved in decane across the hole. After equilibration, the bilayer was tested to confirm a resistance of more than 100 $\mathrm{G} \Omega$, a noise less than $0.1 \mathrm{pA}$, and the absence of channel activity. Junction potentials were corrected with the zero adjust system of the patch-clamp amplifier (Axopatch 200B; Axon Instruments Inc., Burlingame, California, USA). Proteoliposomes were added to the constantly stirred trans (ground) chamber and allowed to fuse with the lipid bilayer in the presence of a positive $100 \mathrm{mV}$ (cis to trans) potential. When fusion was detected by the presence of channel gating, stirring was stopped, and the fluid in the trans chamber was replaced with a proteoliposome-free solution to prevent fusion of additional channels. Voltage was clamped at different potentials, and the resulting cur- rents recorded with the patch-clamp amplifier. Data were digitized, analyzed, and stored on a CD-ROM using pCLAMP software (Axon Instruments).

Preparation of mammalian expression constructs. New restriction sites at the $5^{\prime}$ and $3^{\prime}$ ends of the full-length coding sequence of hUAT and green fluorescent protein (EGFP; CLONTECH Laboratories Inc., Palo Alto, California, USA) were incorporated using PCR (Table 1), and the sequences were verified. Chimeric fusion constructs appending EGFP to the amino or carboxy terminus of hUAT were prepared by ligation of the hUATand EGFP-coding sequences with the appropriate restriction sites (Table 1) into the expression vector pCDNA3.1(-) (Invitrogen Corp.). Since hUAT contains an internal BamHI site, full-length inserts of hUAT were obtained by partial digestion. Additional constructs were prepared with the FLAG epitope fused to the amino or carboxy terminus of hUAT (Table 1). Two sets of complimentary oligonucleotides were synthesized containing the FLAG sequence and the appropriate restriction sites and were annealed, digested, and inserted into the expression vectors described above, replacing EGFP on the amino or carboxy termini of hUAT.

Expression of bUAT in cultured cells: immunocytochemistry and confocal microscopy. LLC-PK1 porcine renal tubular epithelial cells from American Type Culture Collection (ATCC; Manassas, Virginia, USA) were grown in DMEM supplemented with $10 \%$ FBS, 100 units/ml penicillin, $100 \mu \mathrm{g} / \mathrm{ml}$ streptomycin, and $2 \mathrm{mM}$ L-glutamine (Life Technologies Inc., Rockville, Maryland, USA), and were passaged after treatment with cell-dissociation solution (Sigma-Aldrich, St. Louis, Missouri, USA). Transfections were carried out at $80 \%$ confluence using Effectene (QIAGEN Inc.). Forty-eight hours after transfection $1.5 \mathrm{mg} / \mathrm{ml}$ Geneticin (Life Technologies Inc.) was added and maintained in culture media for at least 2 weeks to select stable populations of transfected cells before plating and fixation. For indirect fluorescence and confocal microscopy, cells were plated on acidwashed coverslips in six-well culture plates or on Transwell clear supports (Corning-Costar Laboratory and Equipment, Corning, New York, USA). When immunocytochemistry was performed, coverslips were coated with $0.02 \%$ rat tail collagen type I (Becton Dickinson Labware, Franklin Lakes, New Jersey, USA) at least 24 hours before cell plating.

For immunocytochemistry cells stably transfected with hUAT/FLAG constructs were fixed for 2 minutes in $2 \%$ paraformaldehyde (PFA; Electron Microscopy Science, Ft. Washington, Pennsylvania, USA) in PBS 2 days after plating. Cells were then washed three times in 0.3 $\mathrm{M}$ glycine. Some cells were permeabilized in $0.1 \%$ Triton X-100 in PBS for 5 minutes while the remainder were placed in Triton-free PBS for 5 minutes. Permeabilized and nonpermeabilized cells were subsequently handled identically. After washing in PBS, cells were incubated for 1 hour in blocking solution - 5\% BSA and 10\% normal goat serum (NGS; Sigma-Aldrich) in PBS. Cells were then incubated for 30 minutes in $10 \mu \mathrm{g} / \mathrm{ml}$ anti-FLAG 


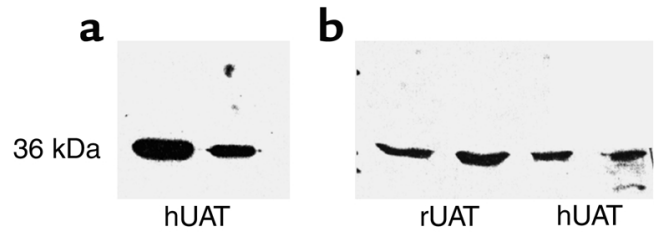

Figure 1

Western blots of recombinant hUAT. (a) A single band at the expected molecular weight of 36-37 kDa is detected with an Ab to the 6-His tag. (b) The rat (rUAT) and human (hUAT) urate transporters both migrate at $36-37 \mathrm{kDa}$ and are detected by a polyclonal $\mathrm{Ab}$ to porcine uricase.

(Sigma-Aldrich) and 1\% NGS in PBS: M2 anti-FLAG was used to detect carboxy-terminal FLAG epitopes and M5 anti-FLAG for amino-terminal epitopes. After washing in PBS, cells were incubated in FITC-conjugated goat anti-mouse IgG (Jackson ImmunoResearch Laboratories Inc., West Grove, Pennsylvania, USA) diluted 1:200 in 1\% NGS in PBS. After washes in PBS, cells were placed in $0.1 \%$ Triton X-100 in PBS for 5 minutes, washed in PBS, then mounted on slides with Vectashield mounting medium. For confocal microscopy cells stably transfected with hUAT/EGFP constructs were fixed for 5 minutes in $4 \%$ PFA in PBS up to 7 days after plating. After fixation, coverslips were mounted onto slides using Vectashield (Vector Laboratories Inc., Burlingame, California, USA) and sealed with clear nail polish.

Fluorescence microscopy was performed with a Zeiss Axioscop (Carl Zeiss Inc., Thornwood, New York, USA). After bright-field and fluorescence images were captured through the appropriate filter cubes and phase rings, they were imported directly into Photoshop (Adobe Systems Inc., San Jose, California, USA). In studies of permeabilized versus nonpermeabilized cells, images were obtained using identical exposure times, and all fields imaged were of equal size. Confocal microscopy was performed with a LEICA TCS-SP confocal laser scanning microscope (Leica Microsystems, Heidelberg, Germany) equipped with argon, krypton, and HeNe lasers. Green images (EGFP or FITC) were obtained after excitation at $492 \mathrm{~nm}$. Confocal images were captured in the GlowOvUn look-up table and were pseudocolored appropriately as green before being saved as TCS export TIFF image files. Images were then imported into Photoshop for analysis and processing. Cell-surface biotinylation. Biotinylation of cell-surface proteins was performed utilizing the one-step recovery method (38) with $150 \mathrm{mM} \mathrm{NaCl}, \mathrm{pH} 9.0$, as the biotinylation solution buffer. Stably transfected LLCPK1 cells $\left(3 \times 10^{5}\right)$ were plated on $0.4-\mu \mathrm{m}$ pore, $24 \mathrm{~mm}$ polycarbonate Transwell supports (Corning-Costar) 10 days before biotinylation. Monolayers were washed once with serum-free DMEM and then twice in PBS plus $\mathrm{Ca}$ and $\mathrm{Mg}$. Apical and basolateral sides of the cell monolayers were then incubated twice in a solution containing $1.5 \mathrm{mg} / \mathrm{ml}$ sulfo-NHS-SS-biotin (Pierce Chemical Co., Rockford, Illinois, USA). All solutions and cells were maintained at $4{ }^{\circ} \mathrm{C}$. The biotinylation reaction was then quenched with a glycine-containing buffer. The cells were rinsed with PBS plus $\mathrm{Ca}$ and $\mathrm{Mg}$, the filters excised from the Transwell housing, the monolayers solubilized in $1 \mathrm{ml}$ of lysis buffer, and the lysate was cleared by centrifugation. The supernatant was incubated overnight with end-over-end rotation with $100 \mu$ l of Immunopure immobilized streptavidin protein complexes (Pierce Chemical Co.). After washing the beads three times in lysis buffer, twice with the high-salt wash solution, and once with the low-salt wash solution, the beads were heated in $100 \mu \mathrm{l}$ of elution solution. Aliquots of samples eluted from the streptavidin beads were evaluated by Western blot analysis, as described above, using monoclonal mouse anti-GFP IgG (CLONTECH Laboratories Inc.) diluted $1: 500$ in $5 \%$ nonfat milk/PBS.

Genomic structure of $b U A T$. The partial sequence of the DUAT gene and intron-exon boundaries of bUAT were determined by preparing PCR fragments from normal human DNA that spanned the length of the bUAT gene using overlapping primer sets generated from the hUAT cDNA sequence. PCR performed using the Expand Long Template PCR kit with buffer 3 (Roche Molecular Biochemicals) yielded six fragments from 0.6 to $7 \mathrm{~kb}$ in length that spanned approximately $18 \mathrm{~kb}$ of genomic DNA. Fragments were cloned into plasmid vectors using the TOPO XL kit (Invitrogen Inc.) and the ends

\section{a}

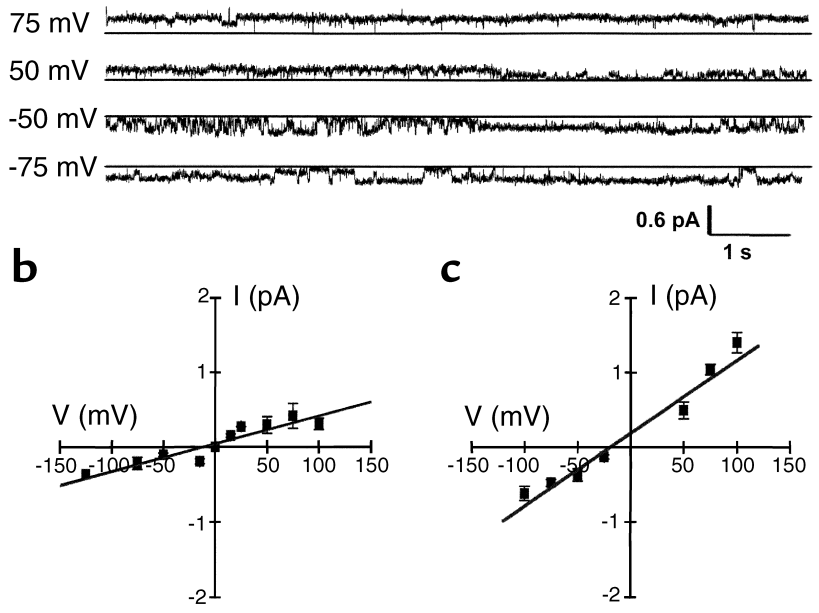

Figure 2

Representative traces and current/voltage relationship of hUAT channel activity in lipid bilayers. (a) Channel activity at various holding potentials $(\mathrm{mV})$ in symmetrical urate solutions of $2.5 \mathrm{mM}$ urate, 220 $\mathrm{mM} \mathrm{Cs}_{2} \mathrm{SO}_{4}$, and $10 \mathrm{mM} \mathrm{HEPES}-\mathrm{NaOH}$ at $\mathrm{pH} 7.4$ after hUAT containing proteoliposomes fused with the planar lipid bilayer. Solid horizontal lines indicate the closed state. (b) Current/voltage (I/V) relationship of the hUAT channel in symmetrical urate solutions. Data represent the mean \pm SE in 11 experiments. The solid line represents the best fit by linear regression analysis $(r=0.97)$ of $G$, the slope conductance in picosiemens $(\mathrm{pS})$. (c) Current/voltage (I/V) relationship of the hUAT channel in the presence of a 10:1 urate gradient $(2.5$ $\mathrm{mM}$ trans $/ 0.25 \mathrm{mM}$ cis). Data represent the mean $\pm \mathrm{SE}$ in four experiments. The solid line represents the best fit by linear regression analysis $(r=0.97)$ of $G$, the slope conductance in picosiemens $(\mathrm{pS})$. 


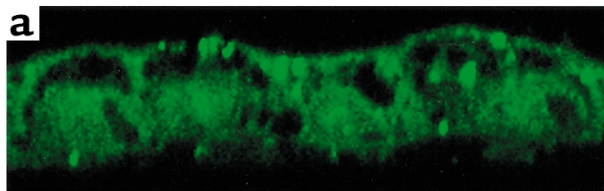

b

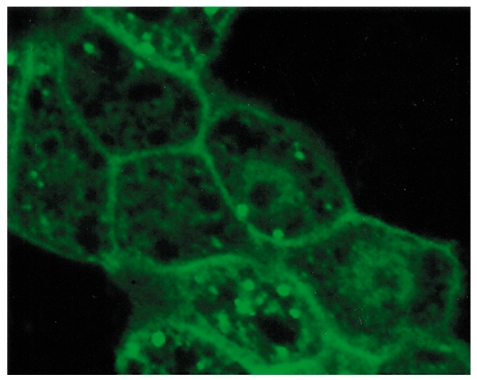

Figure 3

Confocal microscopy of stably transfected LLC-PK1 cells expressing EGFP fused to the carboxy terminus of the urate transporter (hUATEGFP). (a) Sagittal confocal image and (b) horizontal confocal image of cells grown for 6 days on Transwell clear permeable filter supports.

were sequenced. Subsequently, additional primers were generated and vectors resequenced to allow detection of all the intron-exon boundaries. This procedure also detected a second, highly homologous gene (bUAT2) that was amplified by PCR primers to $b U A T$. Sequencing of human DNA and human bacterial artificial chromosome (BAC) clones containing $b U A T$ (see below) allowed determination of the intron/exon boundaries for both genes.

Chromosomal localization of hUAT. Chromosomal localization of the $b U A T$ gene was performed in two ways. First, primers that amplify exon 4 of $b U A T$ were used to amplify DNA from the Stanford G3 human radiation hybrid panel according to the recommended protocol (Research Genetics, Huntsville, Alabama, USA). When it became evident that the original primers would also amplify $b U A T 2$, the panel was rescreened with new bUAT- or $b U A T 2$-specific primers (Table 1). Second, fluorescence in situ hybridization (FISH) of normal human chromosome spreads was performed. BAC clones $305 \mathrm{~N} 23$ and 452D14 were isolated using PCR screening from a human BAC clone library CITB-HSP$C$ by Research Genetics using primers for exon 4 of DUAT. These clones were confirmed to contain $b U A T$ using long PCR and sequencing. The BACs were labeled by nick translation using either digoxigenin-labeled (452D14) or biotin-labeled (305N23) nucleotides and the Roche Molecular Biochemicals kit; completed labeling/nicking was confirmed by gel electrophoresis and the reaction stopped with EDTA. Metaphase chromosome spreads were obtained from phytohemagglutinin-stimulated PBMCs of a normal subject using conventional cytogenetic methods. FISH mapping was performed using methods described previously (39). Briefly, $400 \mathrm{ng}$ of nick-translated DNA probe was applied to each slide, and hybridization was carried out for 48 hours at $37^{\circ} \mathrm{C}$. After posthybridization washing, hybridized probes were detected by avidin-FITC (BAC
452D14) or anti-digoxigenin-Cy3 (BAC 305N23) binding. FISH images were obtained using a Zeiss microscope connected to a Cytovision System (Applied Imaging, Santa Clara, California, USA). Chromosomal localization was assigned by two independent cytogeneticists on the basis of chromosome morphology and 4',6-diamidine-2-phenylindole dihydrochloride (DAPI) staining of chromosomes.

PCR of buman cDNA panels. The levels of expression of hUAT and hUAT2 were assessed by PCR with $b U A T$ - or bUAT2-specific primers in normalized first-strand cDNA panels from human tissues (human multipletissue cDNA [MTC] panels I and II; CLONTECH Laboratories Inc.). PCR of $0.6 \mathrm{ng}$ of each cDNA was performed with Amplitaq Gold (Applied Biosystems, Foster City, California, USA), using an annealing temperature of $60^{\circ} \mathrm{C}$. PCR products were sequenced to confirm specific amplification of either hUAT or hUAT2. Data from the cDNA panels suggested that hUAT2 was expressed at very low levels compared with hUAT (see Results). To assure that the differences in expression did not result from disparate efficiencies of the $b U A T$ versus $b U A T 2$ primer pairs, PCR was performed with these primers using genomic DNA as a template with the Expand Long Template PCR kit in buffer number 1 (Roche Molecular Biochemicals).

Distribution of $h U A T m R N A$. Since expression of hUAT was much greater than hUAT2 in the MTC panels, tissue levels of hUAT expression were determined by Northern analysis and dot-blot array. Messenger RNA ( $1 \mu \mathrm{g} / \mathrm{lane}$ ) from PBMCs was separated by electrophoresis in $0.6 \%$ formaldehyde gels in Mops buffer, then transferred by positive pressure to Nytran nylon membranes in $6 \times$ SSC. Blots were prehybridized for 3 hours in Hybrisol I hybridization solution (Intergen Co., Purchase, New York, USA) at $42^{\circ} \mathrm{C}$. A 180 -bp probe generated by PCR from the linker region (amino acids 126-186) of hUAT that is nonhomologous to other galectins was labeled to a specific activity of greater than $10^{9}$ disintegrations per minute per microgram $(\mathrm{dpm} / \mu \mathrm{g})$ by random priming using the NEBlot

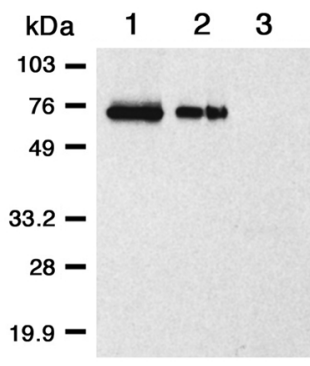

\section{Figure 4}

Western blot of surface biotinylated proteins harvested from stable pools of LLC-PK1 cells expressing hUAT/EGFP chimeric proteins or EGFP without hUAT. Lanes 1-3 contain eluates from LLC-PK1 cells transfected with constructs containing EGFP on the amino terminus of hUAT (lane 1), the carboxy terminus of hUAT (lane 2), and EGFP alone (lane 3). Lanes 1 and 3 contain $5 \mu$ l eluate; lane 2 contains approximately $0.3 \mu$ l eluate. 


\section{Figure 5}

Bright-field, fluorescent, and confocal microscopy of nonpermeabilized and permeabilized stable pools of LLC-PK1 cells expressing hUAT/FLAG chimeric proteins. (a-d and i) Cells transfected with constructs containing FLAG on the amino terminus of hUAT. (e-h and $\mathbf{j}$ ) Cells transfected with constructs containing FLAG on the carboxy terminus of hUAT. (a, $\mathbf{c}, \mathbf{e}$, and g) Bright-field images of nonpermeabilized ( $\mathbf{a}$ and $\mathbf{e})$ and permeabilized ( $\mathbf{c}$ and $\mathbf{g}$ ) cells. (b, $\mathbf{d}, \mathbf{f}$, and $\mathbf{h}$ ) Fluorescent images of nonpermeabilized ( $\mathbf{b}$ and $\mathbf{f}$ ) and permeabilized ( $\mathbf{d}$ and $\mathbf{h}$ ) cells. ( $\mathbf{i}$ and $\mathbf{j}$ ) Confocal images of permeabilized cells.
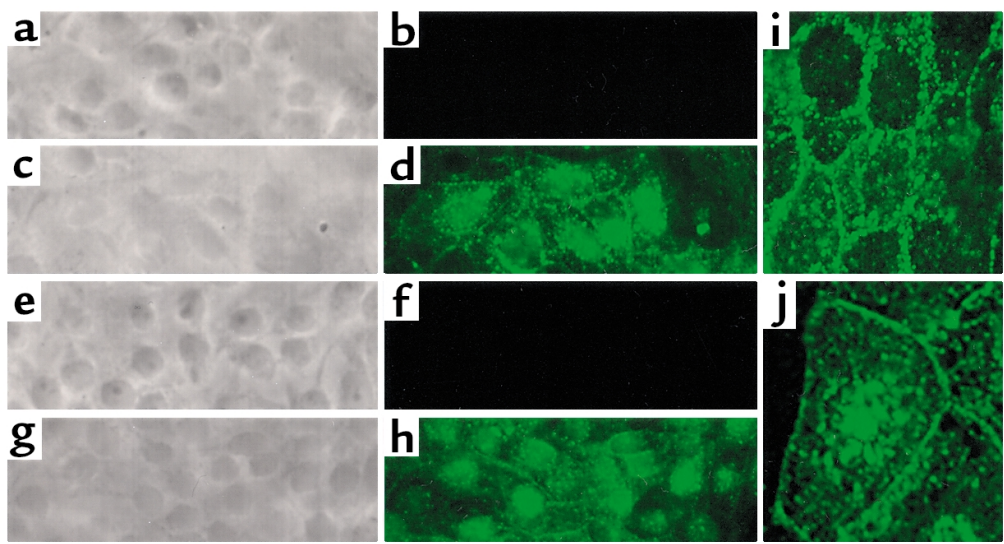

kit (New England Biolabs, Beverly, Massachusetts, USA), then purified on a G25 Sepharose spin column (Eppendorf-5 Prime Inc., Boulder, Colorado, USA). Probe $\left(2 \times 10^{7} \mathrm{dpm}\right)$ was denatured at $100^{\circ} \mathrm{C}$, added to the hybridization bottles, and blots were hybridized 16 hours at $42^{\circ} \mathrm{C}$. Membranes were washed at a final stringency of $65^{\circ} \mathrm{C}$ in $0.1 \times \mathrm{SSC}, 0.1 \%$ SDS for 15 minutes, then developed on $\mathrm{x}$-ray film at $-70^{\circ} \mathrm{C}$. A human multiple-tissue expression (MTE) array containing 76 tissue-specific poly(A) RNAs (CLONTECH Laboratories Inc.) was prehybridized in ExpressHyb hybridization solution (CLONTECH Laboratories Inc.) containing denatured salmon testes DNA for 30 minutes at $65^{\circ} \mathrm{C}$, then hybridized for 16 hours at $65^{\circ} \mathrm{C}$ with the linker probe denatured in Cot- 1 DNA $(150 \mu \mathrm{g} / \mathrm{ml}$; Roche Molecular Biochemicals), salmon testes DNA (750 $\mu \mathrm{g} / \mathrm{ml}), 4 \times \mathrm{SSC}$ at $100^{\circ} \mathrm{C}$, then added to ExpressHyb. The MTE array was washed four times with $2 \times \mathrm{SSC}, 1 \%$ SDS at $65^{\circ} \mathrm{C}$, twice with $0.1 \times \mathrm{SSC}, 0.5 \% \mathrm{SDS}$ at $55^{\circ} \mathrm{C}$, then developed on $\mathrm{x}$-ray film at $-70^{\circ} \mathrm{C}$. The blot was stripped by boiling in $0.5 \%$ SDS, then rehybridized with a 1:1 mixture of probe to GAPDH and ubiquitin, each

EXON 1

hUAT CTTTGTTAAGTCGTTCCCTCTACAAAGGACTICCTÄGTGGGTGTGAAAGGCAGCGGTGGCCACAGAGGCGGCGGAGAGATGGCCTTCAGCGGTTCCCAGGCTCCCTACCTGAGTCCA. .GCT hUAT2 CTTTGTTAAGTCATTCCTTCTGCAAAGGACTGCCTGGCAGGTGTCAAAGGCAGTGGTGGCCACAGAGGCGGTGGAGAGATGGCCTTCAGCGGTTGCCAGGCTCCCTATCTGAGCCCA. . GCC EXON 2

hUAT GTCCCCTTTTCTGGGACTATTCAAGGAGGTCTCCAGGACGGACTTCAGATCACTGTCAATGGGACCGTTCTCAGCTCCAGTGGAACCAG . . GTTTGCTGTGAACTTTCAGACTGGCTTCAGT hUAT2 GTCCCCTTTTCTGGGACTATCCAAGGGGGTCTCCAGGACGGATTTCAGATCACTGTCAATGGGGCCGTTCTCAGCTGCAGTGGAACCAG . GTTTGCTGTGGACTTTCAGACGGGCTTCAGT

hUAT GGAAATGACATTGCCTTCCACTTCAACCCTCGGTTTGAAGATGGAGGGTACGTGGTGTGCAACACGAGGCAGAACGGAAGTGGGGGCCCGAGGAGAGGAAGACACACATGCCTTTCCAG hUAT2 GGAAACGACATTGCCTTCCACTTCAACCCTCGGTTTGAAGACGGAGGGTATGTGGTGTGCAACACGAGGCAGAAAGGAACATGGGGGCCCGAGGAGAGGAAGATGCACATGCCCTTCCAG

hUAT AAGGGGATGCCCTTTGACCTCTGCTTCCTGGTGCAGAGCTCAGATTTCAAG. . GTGATGGTGAACGGGATCCTCTTCGTGCAGTACTTCCACCGCGTGCCCTTCCACCGTGTGGACACCATC hUAT2 AAGGGGATGCCCTTTGACCTCTGCTTCCTGGTGCAGAGCTCAGATTTCAAG. . GTGATGGTGAACGGGATCCTCTTCGTGCAGTACTTCCACCGCGTGCCCTTCCACCGTGTGGACACCATC

DXON 5

hUAT TCCGTCAATGGCTCTGTGCAGCTGTCCTACATCAGCTTCCAG. AACCCCCGCACAGTCCCTGTTCAGCCTGCCTTCTCCACGGTGCCGTTCTCCCAGCCTGTCTGTTTCCCACCCAGGCCC hUAT2 TCCGTCAATGGCTCTGTGCAGCTGTCCTACATCAGCTTCCAG. . AATCCCCGCGCAGTCCCCGTTCAGCCTGCCTTCTCCACGGTGCCGTTCTCCCAGCCTGTCTGTTTCCCACCCAGGCCC $\begin{array}{ccc}\text { EXON } \mathbf{6} & \text { EXON } \mathbf{7} \\ \text { hUAT AGGGGGCGCAGACAAAAA. . CCTCCCGGCGTGTGGCCTGCCAACCCGGCTCCCATT. . ACCCAGACAGTCATCCACACAGTGCAGAGCGCCCCTGGACAGATGTTCTCT. . ACTCCCGCCATCI }\end{array}$ hUAT2 AGGGGGCGCAGACAAAAA. . CCTCCCAGCGTGCGGCCTGCCAACCCAGCTCCCATT. . ACCCAGACAGTCATCCACACGGTGCAGAGTGCCTCTGGACAGATGTTCTCT . ACTCCCGCCATC EXON 9

hUAT CCTATGATGTACCCCCACCCCGCCTAT . .CCGATGCCTTTCATCACCACCATTCTGGGAGGGCTGTACCCATCCAAGTCCATCCTCCTGTCAGGCACTGTCCTGCCCAGTGCTCAGAG . GTT hUAT2 CCTATGATGTACCCCCACCCTGCCTAT . . CCGATGCCTTTCATCACCACCATTCCGGGAGGGCTGTACCCATCCAAGTCCATCATCCTGTCAGGCACTGTCCTGCCCAGTGCTCAGAG. . GTT hUAT2 CCTATGATGTACCCCCACCCTGCCTAT. . CCGATGCCTTTCATC
EXON 10

hUAT CACATCAACCTGTGCTCTGGGAACCACATCGCCTTCCACCTGAACCCCCGTTTTGATGAGAATGCTGTGGTCCGCAACACCCAGATCGACAACTCCTGGGGGTCTGAGGAGCGAAGTCTG hUAT2 CACATCAACCTGTGCTCTGGGAGCCACATCGCCTTCCACATGAACCCCCGTTTTGATGAGAATGCTGTGGTCCGTAACACCCAGATCAACAACTCITGGGGGTCTGAGGAGCGAAGTCTG Exon 11

hUAT CCCCGAAAAATGCCCTTCGTCCGTGGCCAGAGCTTCTCA. . GTGTGGATCTTGTGTGAAGCTCACTGCCTCAAGGTGGCCGTGGATGGTCAGCACCTGTTTGAATACTACCATCGCCTGAGG hUAT2 CCCCGAAAAATGCCCTTCGTCCGÄGGCCAGAGCTTCTCG. . GTGTGGATCTTGTGTGAAGCTCACTGCCTCAAGGTGGCCGTGGATGGTCAGCACGTGTTTGAATACTACCATCGCCTGAGG

hUAT AACCTGCCCACCATCAACAGACTGGAAGTGGGGGGCGACATCCAGCTGACCCATGTGCAGACATAGGCGGCTTCCTGGCCCTGGGGCCGGGGGCTGGGGTGTGGGGCAGTCTGGGTCCTC hUAT2 AACCTGCCCACCATCAACAAACTGGAAGTGGGTGGCGACATCCAGCTGACCCACGTGCAGACATAGGCGGCTCCCTGGCCCTGGGGCCGGGGGCTGGGGTGTGGGGCAGTCTGGGTCCTC

hUAT TCATCATCCCCACTTCCCAGGCCCAGCCTTTCCAACCCTGCCTGGGATCTGGGCTTTAATGCAGAGGCCATGTCCTTGTCTGGTCCTGCTTCTGGCTACAGCCACCCTGGAACGGAGAAG hUAT2 TCATCATCCCCACTTCCCAGGCCCAGCCTTTCCAACCGTGCCTGGGATCTGGGCTTTAATGCAGAGGCCATGTCCTTATCTGGTCCTGCTTCTGGCTACAGCCACCCTGGAATCGAGAAG

hUAT GCAGCTGACGGGGATTGCCTTCCTCAGCCGCAGCAGCACCTGGGGCTCCAGCTGCTGGAATCCTACCATCCCAGGAGGCAGGCACAGCCAGGGAGAGGGGAGGAGTGGGCAGTGAAGATG hUAT2 GCAGCTGACTGGGATTGCCTTCCTCAGCCGCAGCAGCACCTGGGGCGCCAGCTGCTGGAATCCTACAAACCCAGAAGGCGGGCACAGCCAGGGAGAGGGGAGGAGTGGGCAGTGAAGATG

hUAT AAGCCCCATGCTCAGTCCCCTCCCATCCCCCACGCAGCTCCACCCCAGTCCCAAGCCACCAGCTGTCTGCTCCTGGTGGGAGGTGGCCTCCTCAGCCCCTCCTCTCTGACCTTTAACCTC hUAT2 AAGCCCCATGCTCAGTCCCCTCCCATCCCCCACGCAGCTCCACCCCAGTCTCAAGCCACCAGCTGTCTGCTCCTGGTGGGAGATGGCCTCCTCAGCCCCTCCTCTCTGACCTTTAACCTC

hUAT ACTCTCACCTTGCACCGTGCACCAACCCTTCACCCCTCCTGGAAAGCAGGCCTGATGGCTTCCCACTGGCCTCCACCACCTGACCAGAGTGTTCTCTTCAGAGGACTGGCTCCTTTCCCA hUAT2 АСTCTCACCTTGCACCСTGCACCAACCCTTCACCCCTCCTGGAAAGCAGGCCTGATGGCTTCCCACTGGCCTCCACCAACTGACCAGAGTGTTCTCTTCAGGGGACTGGCTCCTTTCCCA

hUAT GTGTCCTTAAAATAAagAAATGAAAATGCTTGTTGGCAC

hUAT GTGTCCTTAAAATAAAGAAATGAAAATGCTTGTTGGCAC

\section{Figure 6}

Comparison of the nucleotide sequences of hUAT and hUAT2. The sequence of hUAT2 is a composite of our sequencing efforts and HTGS rough-draft sequence from Genbank accession number AL353997.2. Shaded letters indicate nucleotide differences between the sequences. The 11 exons are each labeled and separated by periods. 
hUAT MAFSGSQAPYLSPAVPFSGTIQGGLQDGLQITVNGTVLSSSGTRF hUAT2 MAFSGCQAPYLSPAVPFSGTIQGGLQDGFQITVNGAVLSCSGTRF

hUAT AVNFQTGFSGNDIAFHFNPRFEDGGYVVCNTRQNGSWGPEERKTH hUAT2 AVDFQTGFSGNDIAFHFNPRFEDGGYVVCNTRQKGTWGPEERKMH

hUAT MPFQKGMPFDLCFLVQSSDFKVMVNGI LFVQYFHRVPFHRVDTIS hUAT2 MPFQKGMPFDLCFLVQSSDFKVMVNGSLFVQYFHRVPFHRVDTIS

Exon 5- intestinal isoform

hUAT VNGSVQLSYISFQ NPRTVPVQPAFSTVPFSQPVCFPPRPRGRRQK hUAT2 VNGSVQLSYISFQ NPRAVPVQPAFSTVPFSQPVCFPPRPRGRRQK

hUAT PPGVWPANPAPITQTVIHTVQSAPGQMFSTPAIPPMMYPHPAYPM hUAT2 PPSVR PANPAPITQTVIHTVQSASGQMFSTPAIPPMMYPHPAYPM

hUAT PFITTILGGLYPSKSILLSGTVLPSAQR FHINLCSGNHIAFHLNP hUAT2 PFITTIPGGLYPSKSIILSGTVLPSAQR FHINLCSGSHIAFHMNP

\section{Exon 10}

hUAT RFDENAVVRNTQIDNSWGSEERSLPRKMPFVRGQSFS VWILCEAH hUAT2 RFDENAVVRNTQINNSWGSEERSLPRKMPFVRGQSFS VWILCEAH

hUAT CLKVAVDGQHLFEYYHRLRNLPTINRLEVGCDIQLTHVQT hUAT2 CLKVAVDGQHVFEYYHRLRNLPTINKLEVGGDIQLTHVQT

\section{Figure 7}

Comparison of the putative amino acid sequences of hUAT and hUAT2. Shaded letters indicate amino acid differences between the sequences. Amino acids coded for by exons 5 and 10 are demarcated by spaces and a line over the sequence. Amino acids within exon 10 that are in boldface constitute the signature for the second $\beta$-galactoside-binding domain.

of which are reported by the manufacturer to demonstrate relatively uniform expression in the tissues represented on the MTE array. Films of the hUAT and GAPDH/ubiquitin signals were scanned into Photoshop using a flatbed scanner, the intensity of each spot was measured using UN-SCAN-IT software (Silk Scientific, Orem, Utah, USA), and the ratio of hUAT to $\mathrm{GAPDH} /$ ubiquitin expression calculated.

\section{Results}

Nucleotide and amino acid sequences of $b U A T$. Comparison of the sequences of hUAT and human galectin 9 (Genbank accession number $Z 49107)$ reveals four nucleotide differences, each of which results in a change in the encoded amino acid: human galectin 9 is reported as arginine, phenylalanine, leucine, and proline at amino acids 88, 135,238 , and 281 (24), while hUAT encodes lysine, serine, proline, and glutamic acid. However, the amino acid sequence of hUAT is identical to that of an unpublished intestinal isoform of human galectin 9, except for the additional block of 32 amino acids (residues 149-180) that defines this isoform (Genbank accession number AB006782). Moreover, although the amino acid sequence of hUAT differs by one amino acid from the originally reported sequence of ecalectin (Genbank accession number AB0005894) (25), reanalysis revealed a sequencing error (26). The corrected amino acid 5 of ecalectin, a glycine rather than serine, is now identical to that in hUAT, the intestinal isoform, and galectin 9. The identity of sequences of hUAT, ecalectin (26), and the intestinal isoform suggest that the four-amino acid differences between these and the human galectin 9 sequence (24) likely reflect sequencing errors in the latter.
Expression of recombinant bUAT protein. Western blot analysis using an $\mathrm{Ab}$ to the histidine tag (Figure 1a) reveals that recombinant hUAT approximates 36-37 $\mathrm{kDa}$, as expected. Western blot analysis also demonstrates that recombinant hUAT is reactive to an affinity-purified polyclonal $\mathrm{Ab}$ to porcine uricase and is identical in size to rUAT (Figure 1b). Reactivity of hUAT to antiuricase was evaluated because immunoreactivity to this $\mathrm{Ab}$ previously served to detect both the plaque in a rat cDNA library that expressed rUAT, critical to cloning rUAT, and to identify the size of recombinant rUAT protein (20).

Functional evaluation of recombinant $b U A T$. As demonstrated in Figure 2a, channel activity (clear transitions between open and closed states) was detected in symmetrical urate solutions when recombinant hUAT protein fused with the lipid bilayer. Channel activity was never detected in the absence of either recombinant hUAT or urate in the bathing media (not depicted). In symmetrical urate solutions the current/voltage relationship is linear with an equilibrium potential of $0 \mathrm{mV}$ and a slope conductance of $4.0 \pm 0.4$ picosiemens (pS), $n=11$ (Figure $2 \mathrm{~b}$ ). The equilibrium potential and slope were not altered significantly in the presence of tenfold gradients of $\mathrm{Cs}^{+}$or $\mathrm{SO}_{4}{ }^{2-}$ or an infinite gradient of $\mathrm{Ca}^{++}$ (not depicted), implying that the reconstituted channel is minimally permeant to these ions and that the current is carried by urate. In contrast, creation of a 10:1 trans/cis urate gradient (Figure 2c) resulted in a significant shift $(P<0.01)$ in the reversal potential to $-18.0 \pm 2.3 \mathrm{mV}$ $(n=4)$, with a slope conductance of $10 \pm 1.0 \mathrm{pS}$. These findings indicate that the channel is highly selective for urate relative to other ions in the solutions bathing the reconstituted channel (>100-fold).

Expression of bUAT in mammalian epithelial cells. To determine if hUAT is targeted to plasma membranes in living cells, the localization of hUAT/EGFP chimeric proteins has been assessed in a stably transfected immortalized renal epithelial cell line, LLC-PK1, which is known to polarize in culture (40). As demonstrated in sagittal (Figure 3a) and horizontal (Figure 3b) confocal images, hUAT is targeted to both apical and basolateral plasma membranes.

\section{Table 2}

Exons in the hUAT gene

\begin{tabular}{lc}
\cline { 2 - 2 } Exon number & Nucleotides \\
Exon 1 & $1-120$ \\
Exon 2 & $121-212$ \\
Exon 3 & $213-414$ \\
Exon 4 & $415-525$ \\
Exon 5 & $526-621$ \\
Exon 6 & $622-657$ \\
Exon 7 & $658-708$ \\
Exon 8 & $709-750$ \\
Exon 9 & $751-839$ \\
Exon 10 & $840-1002$ \\
Exon 11 & $1003-1725$
\end{tabular}

Numbers represent the nucleotides in the Genbank sequence for the galectin 9 , intestinal isoform, accession number AB006782, which is identical to our sequence for hUAT. 


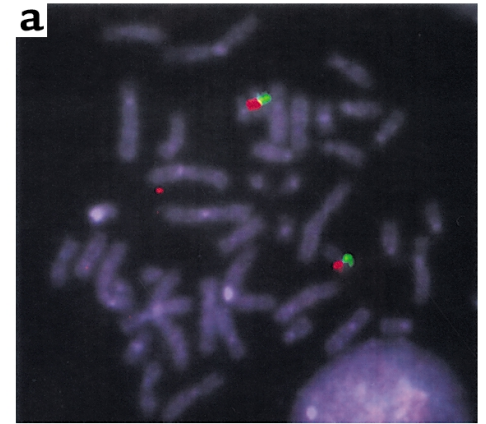

b

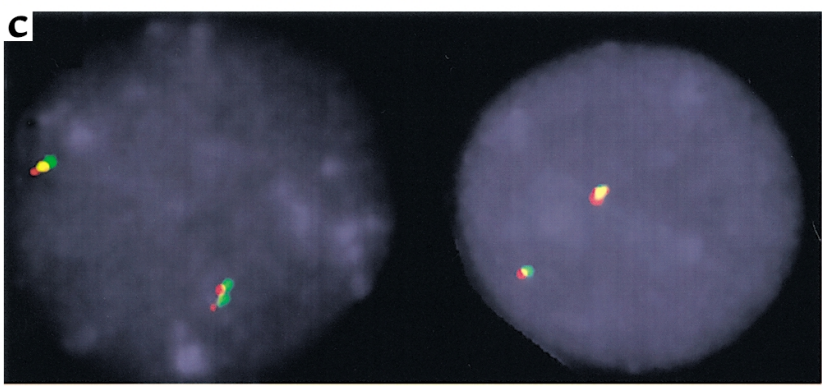

Figure 8

(a) FISH of BAC probes for $h$ UAT to metaphase chromosomes. Chromosomes fluoresce blue with DAPI. The green fluorescent signal results from avidin-FITC binding to the biotin-labeled BAC 452D14 probe for $h \cup A T$, and the red signal reflects anti-digoxigenin-Cy3 binding to the digoxigenin-labeled BAC 305N23 probe. Both probes bind to the same region of each chromosome 17 in the metaphase. (b) Enlarged image demonstrating overlapping labeling by both probes of the centromeric region of the short arm of chromosome 17. (c) Interphase nuclei demonstrating overlapping binding of the two BAC probes for $h U A T$. (d) Ideogram of chromosome 17 depicting the localization of $h U A T$ and $h U A T 2$. PCR of the Stanford G3 radiation hybrid panel with primers specific for hUAT or hUAT2 indicates that hUAT (marker D17S2123) and hUAT2 (D17S1857) map to nearby markers on the short arm of chromosome 17 between $17 \mathrm{p} 11.2$ and $17 \mathrm{p} 12$.

hUAT/EGFP constructs, but not EGFP alone, these findings require that hUAT contains at least one extracellular domain that binds biotin.

In our previously published model for rUAT based on computer-assisted modeling and experimental data in lipid bilayer studies, it was proposed that rUAT contains four transmembrane domains, with intracellular amino and carboxy termini (21). Based on the high degree of homology between rUAT and hUAT, we tested the hypothesis that hUAT would have a similar topology. Despite the presence of numerous cells (Figure 5, a and e) neither amino nor carboxy termini hUAT/FLAG fusion proteins were detected in nonpermeabilized, stably transfected LLCPK1 cells (Figure 5, b and f), indicating that neither terminus was exposed on the cell surface. In contrast, in a comparable number of cells (Figure 5, c and g), both chimeric proteins were clearly evident in paired cells that were permeabilized

To assess whether the membrane localization of hUAT in stably transfected LLC-PK1 cells simply represents a close association of hUAT with the membrane or whether hUAT is, in fact, a transmembrane protein, cell-surface biotinylation studies were performed using sulfo-NHS-SS-biotin. This compound is a hydrophilic, membrane-impermeant biotinylation reagent that binds only to primary amine groups of lysine residues in membrane proteins that have exposed extracellular domains $(38,41)$. As depicted in Figure 4, eluates from LLC-PK1 cells transfected with hUAT chimeric constructs with EGFP at either the amino or the carboxy terminus contained bands at approximately 70-75 $\mathrm{kDa}$. Bands were not detected in control eluates of LLC-PK1 cells stably transfected with the intracellular, soluble protein EGFP without hUAT. Since EGFP contains 20 lysines that would be reactive had they been accessible to the sulfo-NHS-SS-biotin $(38,41)$, this finding indicates that the reagent did not penetrate the plasma membrane of the LLC-PK1 cells. The hUAT/EGFP bands (Figure 4) are slightly larger than anticipated based on the size of the chimeric proteins (hUAT, $36 \mathrm{kDa}$; EGFP, $27 \mathrm{kDa}$ ), since the NHS groups remain bound to hUAT-EGFP when biotinylated proteins are eluted from streptavidin-conjugated beads, restricting protein mobility during electrophoresis (38). Based on the ability to surface biotinylate before application of the same $\mathrm{Ab}$ (Figure $5, \mathrm{~d}$ and $\mathrm{h}$ ). Fluorescence (Figure 5, d and h) and confocal (Figure 5 , $i$ and $j$ ) microscopy images suggest that the amino and carboxy hUAT/FLAG fusion proteins, like hUAT/EGFP (Figure 3), are located in the plasma membrane. Insofar as the FLAG epitopes appended to hUAT can only be detected when cell membranes are permeabilized (Figure 5, d and h), these studies indicate that both the amino and carboxy termini of hUAT, like the termini of rUAT (42), must reside on the cytoplasmic side of the plasma membrane. Taken together, these confocal microscopy, biotinylation, and permeabilization data indicate that hUAT is a transmem-

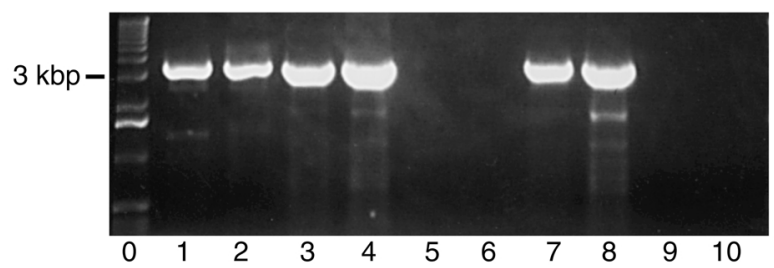

\section{Figure 9}

PCR of human genomic DNA (lanes 1, 2) and BAC clones 452D14 (lanes 3-6) and 305N23 (lanes 7-10). Lanes 1, 3, 4, 7, and 8 are PCR products obtained with hUAT-specific primers. Lanes 2, 5, 6, 9 , and 10 are PCR products obtained with hUAT2-specific primers. Lane 0 is a $1-k b p$ DNA ladder. 


\section{Figure 10}

Comparison of $\mathrm{PCR}$ products amplified from CLONTECH Laboratories Inc. MTC cDNA panels using primers specific for hUAT, hUAT2, or GAPDH. The specific gene amplified is indicated to the left of the figure, the tissue from which the cDNA was isolated at the top, and the size of the $\mathrm{PCR}$ product on the right.

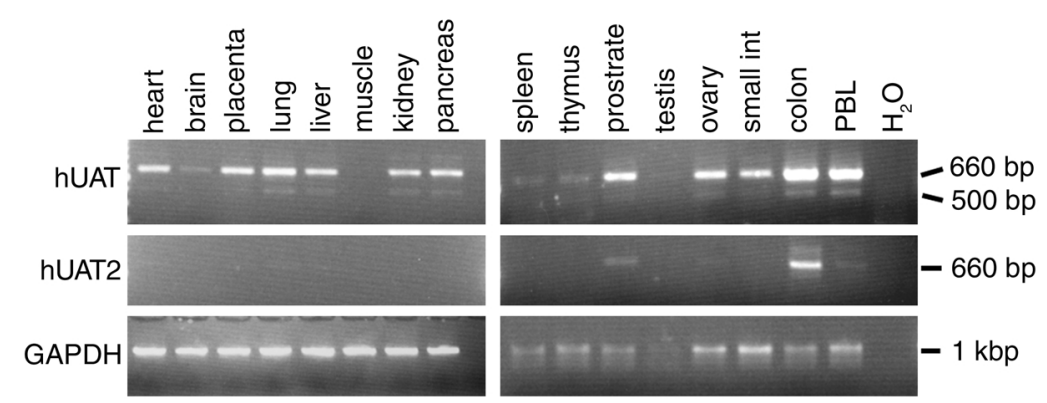

brane protein that is composed of at least one extracellular and two transmembrane domains.

Genomic structure and chromosomal localization of bUAT. The genomic structure and chromosomal localization of the DUAT gene have been determined to facilitate future studies attempting to relate mutations/polymorphisms in $b U A T$ with systemic disorders associated with hyperuricemia. The $B U A T$ gene amplified from normal human genomic DNA using long PCR contains 11 exons (Table 2 ) and spans approximately $18 \mathrm{~kb}$. A novel gene, UUAT2, which is more than $96 \%$ identical to the exons of bUAT (Figure 6) and contains identical putative intron/exon splice junctions to $b U A T$, has also been detected. The projected cDNA for this novel gene contains an open reading frame that would encode a protein that is $94 \%$ identical to hUAT (Figure 7). Both BUAT and BUAT2 have been sequenced as part of the Human Genome Project and are present in the High Throughput Genomic Sequences database at National Center for Biotechnology Information. Comparison of the two genes indicates that they are approximately $90 \%$ identical over the $18 \mathrm{~kb}$ spanned by each of the genes.

To determine the chromosomal localization of hUAT, FISH studies were performed using two BAC clones that contain the bUAT gene, but not bUAT2. Both of these clones hybridized to the short arm of chromosome 17 (Figure 8, a and b, red and green signals). In most cases the signal from the two probes overlapped as expected (yellow signal), both on the metaphase chromosomes (Figure $8 \mathrm{~b}$ ) and, at higher resolution, on the less-condensed interphase chromatin (Figure 8c). This chromosomal localization was confirmed by radiation hybrid mapping using the original primers employed to isolate the BAC clones. As these original primers could potentially amplify both $b U A T$ and $b U A T 2$, radiation hybrid mapping was repeated with $b U A T$ - and $b U A T 2$-specific primers. These studies indicate that $b U A T$ and $b U A T 2$ map to adjacent microsatellite markers (D17S2123 and D17S1857, respectively) between $17 \mathrm{p} 11.2$ and $17 \mathrm{p} 12$ on the short arm of chromosome 17 (Figure 8d). In contrast, a computer search of the human genome sequence in the HTGS database suggests that the bUAT gene may be present on either chromosome 11 or chromosome 4 . However, neither our FISH studies (Figure 8, a-c) nor radiation hybrid mapping of the bUAT genes (Figure 8d) provide any evidence to support mapping of this gene to any chromosome other than 17.
Expression of bUAT mRNA in human tissues. Urate is a product of purine metabolism in all cells, and must be removed from the cells in order to be excreted by the kidney. This would suggest that hUAT might be expressed in a wide variety of tissues. Studies were therefore performed to determine whether hUAT is expressed in a variety of human tissues, and levels of expression were compared to those of the novel gene hUAT2. First, PCR primers and reaction conditions were developed that would specifically amplify either $b U A T$ or $b U A T 2$. As depicted in Figure 9, primers for bUAT and bUAT2 generated products with similar intensity from normal genomic DNA, indicating that these gene-specific primer pairs are approximately equally efficient in amplifying their respective targets: sequencing of PCR products confirmed that the products were specific for bUAT (lane 1) or bUAT2 (lane 2). PCR of BAC clones with these primers was only successful for the bUAT gene (lanes 3-4 and lanes 7-8), indicating that neither BAC clone contained bUAT2 (lanes 5-6 and 9-10). These two sets of primers were employed to amplify normalized cDNA prepared from multiple tissues provided in the CLONTECH Laboratories Inc. human MTC panels. PCR amplification of the CDNA with GAPDH primers was similar in all tissues (Figure 10). Although it may not be evident in the photograph of the gel, hUAT was expressed in all of the tissues in the MTC panels (Figure 10). However, the expression of hUAT relative to GAPDH differed in the various tissues, being barely detectable in testis and muscle. In contrast, expression of hUAT2 was only detectable in a few tissues, most abundantly in prostate, colon, and peripheral blood lymphocytes (PBLs), and in each the expression of

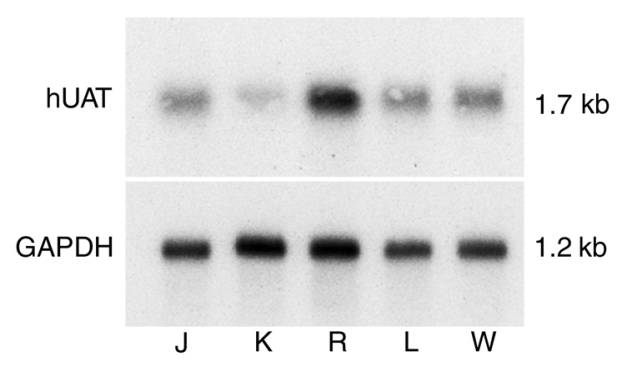

Figure 11

Northern blot of mRNA prepared from PBMCs of five human subjects $(J, K, R, L$, and $W$ ) probed with a cDNA specific for the linker region of hUAT, stripped, then reprobed with a cDNA for GAPDH. 
hUAT was at least severalfold greater than that of hUAT2. Sequencing of the most abundant of the hUAT2 products confirmed that it was hUAT2 that had been amplified rather than nonspecific amplification of hUAT. In the preparation of hUAT cDNA from normal PBMCs, which express the greatest level of hUAT on the MTC panels (Figure 10), PCR products were cloned into plasmid expression vectors and sequenced. Even though the PCR primers and conditions employed were not specific for hUAT, hUAT2 was not detected in any of the 12 plasmid clones that were sequenced. This observation provides further evidence that hUAT2 is expressed at very low levels relative to hUAT.

In addition to demonstrating that hUAT2 has relatively limited tissue expression, amplification of the MTC panel cDNA with hUAT-specific primers detected a second, weaker band that is $162 \mathrm{bp}$ smaller than the expected PCR product, best seen in colon and PBL (Figure 10). Purification and sequencing of this product demonstrated that it is a splice variant of hUAT in which exon 10 is deleted. If expressed, this variant would result in a protein in which 54 amino acids including those that encode the entire second $\beta$-galactoside-binding domain within hUAT are deleted (Figure 7).

The data from the MTC panels suggested that hUAT is nearly ubiquitously expressed in the tissues tested. Although previous studies demonstrated expression of hUAT in a limited number of tissues $(24,25)$, the sensitivity of these data may have been limited by the use of total RNA rather than mRNA. We therefore probed the CLONTECH Laboratories Inc. MTE MRNA array, primarily to evaluate the expression of hUAT. The near identity of hUAT and hUAT2 would make it extremely difficult to distinguish expression of these two genes on Northern blots. However, since the semiquantitative data from the MTC panels indicate that in all tissues screened hUAT is expressed at levels at least severalfold greater than hUAT2, Northern blot analysis of the CLONTECH Laboratories Inc. human mRNA MTE array should reflect primarily the relative levels of expression of hUAT. A hybridization probe consisting of the unique linker region of hUAT was tested on a Northern blot of human mRNA prepared from PBMCs of five human subjects. This probe detected a single mRNA band of the predicted size and no other members of the highly homologous galectin family (Figure 11). It is of interest that there appears to be significant heterogeneity in the levels of expression of hUAT in different subjects (Figure 11). The tissue-specific expression of hUAT was then assessed by using this linker fragment to probe the CLONTECH Laboratories Inc. human mRNA MTE array. The results of hybridization of this unique probe to the MTE array are depicted in Figure 12. The tissues represented on the array and the expression of hUAT relative to the housekeeping genes in these tissues are tabulated in Table 3. As is evident, hUAT is widely expressed in human tissues and cell lines, with levels that vary as much as 200 -fold between tissues/cell lines. 


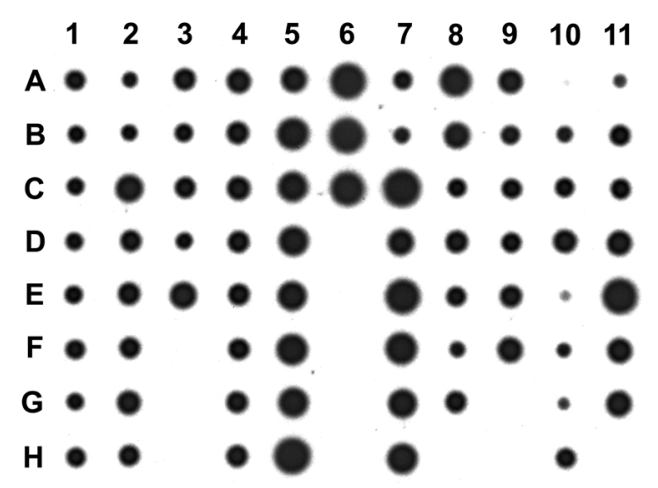

Figure 12

CLONTECH Laboratories Inc. MTE mRNA array hybridized to a cDNA probe specific for the linker region of hUAT. See Table 3 for the identity of each tissue on the blot and the intensity of the hUAT signal relative to that of GAPDH/ubiquitin.

\section{Discussion}

Our studies provide evidence that recombinant protein produced from a nucleotide sequence that is identical to human ecalectin (26) and the intestinal isoform of galectin 9 (minus the 96 nucleotides that define this isoform) and only four nucleotides different from human galectin 9 (24), readily inserts into and functions as a highly selective urate transporter/channel (hUAT) in lipid bilayers (Figure 2). Moreover, these studies document that hUAT resides in plasma membranes (Figure 3 ) as a transmembrane protein with at least one extracellular domain (Figure 4) and cytoplasmic amino and carboxy termini (Figure 5) following stable transfection and expression in a renal epithelial cell line.

We have demonstrated previously that rUAT, a protein with $73 \%$ identity to hUAT, can also be functionally reconstituted as a highly selective urate transporter/channel with many features comparable to that of the rat electrogenic renal urate transporter (10-12, $20,21)$ and have obtained evidence that rUAT is similarly expressed as a transmembrane protein with intracellular amino and carboxy termini in a variety of epithelial-derived cells lines (42). However, the galectin family of proteins has been reported as cytoplasmic or secreted proteins that play a role in diverse functions including cell adhesion, cell migration, cell proliferation, immune function, apoptosis, chemoattraction, and neoplasia $(22-30,32-35,43,44)$. Specifically, human galectin 9 , a protein that is approximately $99 \%$ identical to hUAT, is reported to participate in cell interactions of the immune system (24), whereas ecalectin, a protein that is identical to hUAT, is described as a specific eosinophil chemoattractant (25, 26). It is of interest that a distinctly different function has been ascribed to the highly homologous mouse galectin 9 , induction of apoptosis of thymic T cells (23). Although also considered to be a secreted protein, it is of interest that mouse galectin 9 has been detected at plasma membranes of intestinal, hepatic, and thymic cells (23). Based on our current findings (Figures 2-5) we conclude galectin 9 need not invariably be a cytoplasmic or secreted protein, but rather that it may reside as an integral protein in the lipid bilayer of plasma membranes where it may serve an important transport function, at least in renal epithelial cells. Additionally, insofar as recombinant hUAT functions as a selective urate channel (Figure 2), we suggest that hUAT is likely to be the molecular representation of the electrogenic transporter that functions to secrete urate into the proximal tubule of the human kidney (13). Since excreted urate is generally thought to derive primarily from secreted urate $(45,46)$, perturbations in this transporter could modify the ability of the kidney to eliminate urate from the body.

It has long been known that elevated serum urate levels, most often consequent to renal urate underexcretion (46), are associated with gout. Hyperuricemia is also associated with hypertension (47) and often precedes and predicts its development in adults (48) and adolescents (49), suggesting a causal relationship. Recent studies demonstrate that rats develop hypertension following the induction of hyperuricemia, supporting this hypothesis (50). Hyperuricemia may also play a causal role in renal failure. In families with an inherited syndrome of hyperuricemia, precocious gout, hypertension, and renal failure, fractional urate excretion is reduced (51-55) prior to the onset of renal disease (52-56). There is no evidence of intrarenal urate deposition as a cause of their renal disease $(57,58)$, although some have been labeled as gouty nephropathy (59). Hyperuricemia has also been associated with progression of IgA nephropathy (60) and with increased fibrosis in a rat model of inflammatory renal disease (50). Finally, hyperuricemia may be an independent risk factor for cardiovascular disease (61-65), although this finding is controversial and a mechanism for uric acid-induced pathogenesis is as yet unproven (66-68).

Although studies suggest an association between hyperuricemia and a number of systemic diseases, it seems possible that concomitant elevations in intracellular urate concentrations may play an equal or even more significant role pathogenetically. In this regard, since hUAT mRNA (Figure 12, Table 3 ) is widely expressed and

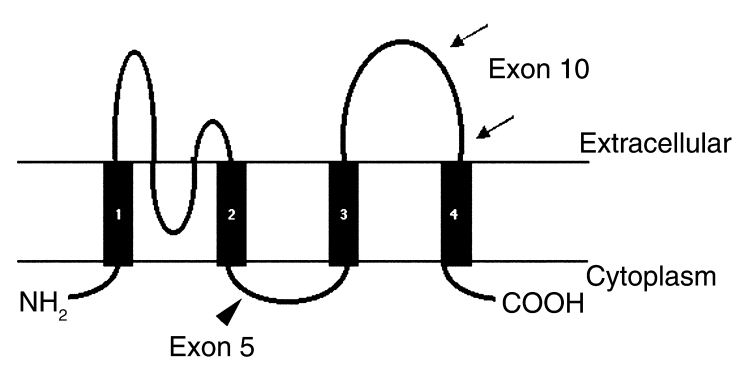

Figure 13

Structural model of hUAT. Numbers $1-4$ indicate transmembrane domains. The arrowhead indicates the site of insertion of 32 amino acids in the intestinal isoform of hUAT. The two arrows demarcate the block of amino acids containing the $\beta$-galactoside-binding site that is deleted in the hUAT isoform in which exon 10 is spliced out. 
hUAT can function as a urate channel in lipid bilayers (Figure 2), inserting as an integral plasma membrane protein (Figures 3-5), it seems likely that hUAT also functions as a transporter in systemic cells to permit urate efflux subsequent to intracellular urate production. While speculative, there is currently no information that even suggests an alternative mechanism to subserve this important housekeeping function in humans.

Insofar as mutations in $b U A T$ could restrict cellular urate efflux as well as renal urate excretion, urate would accumulate intracellularly and, as suggested above, may be causally involved in initiating intracellular events that result in disease (50). To provide a basis for future searches for mutations/polymorphisms in this gene, we have determined the genomic structure and chromosomal localization of bUAT in individuals without disease. These studies indicate that there are three isoforms of hUAT: the 11-exon intestinal isoform (Figures 6 and 7), the much more widely expressed 10-exon isoform in which exon 5 is spliced out (Figure 13), and a newly detected 9-exon isoform in which exons 5 and 10 are deleted (Figure 10). Based on the homology between hUAT and rUAT and our preliminary topologic analysis of hUAT (Figures 4 and 5), it seems likely that the molecular model proposed for rUAT (21) also applies to hUAT. Using this model (Figure 13), it is of interest that insertion of exon 5 introduces a second region of homology to uricase (the presumed urate-binding domain in hUAT) just upstream of the previously identified block of amino acids in rUAT with homology to uricase (21). Deletion of exon 10 eliminates the entire second $\beta$-galactoside-binding site in an extracellular domain of the protein (21). The presence of a second urate-binding site could modify the affinity of hUAT for urate and thereby modify channel function. The functional consequences, if any, of deletion of the $\beta$-galactoside-binding site are unknown: while $\beta$-galactoside-binding sites define the galectin family of proteins, no functional role has as yet been ascribed to these sites.

In sequencing the genomic DNA for $b U A T$ we identified a novel gene, $b U A T 2$, that is highly homologous to bUAT (Figures 6 and 7). Although expressed at much lower levels than hUAT and more limited in its tissue distribution (Figure 10), hUAT2 may also function as a urate transporter. Most importantly, the extremely high degree of homology at both the nucleotide and amino acid levels between hUAT and hUAT2 (Figures 6 and 7) indicate that it will require great care to identify true mutations/polymorphisms in bUAT in subjects with defects in renal urate transport.

In summary, we have presented data that support our hypothesis that hUAT can function as a plasma membrane urate transporter. These studies have provided additional novel data that hUAT may be present as three distinct isoforms that could potentially subserve different cellular or transport functions. We have also identified a novel gene, $b U A T 2$, with a very different expression pattern than $b U A T$ that is also likely to be a urate transporter. Finally, we have reported the genomic structure of $b U A T$ and $b U A T 2$ and have mapped both genes to the short arm of chromosome 17. These data will permit a comparative analysis of the functions of these isoforms and genes to better understand the molecular mechanisms of urate transport. In addition, this information will serve as a basis for defining mutations in the genes for these transporters in patients with disorders of urate excretion and thereby assist in characterizing the molecular mechanisms of the alterations in urate homeostasis in these disorders.

\section{Acknowledgments}

This work was supported by NIH grants DK-57867 (M.S. Lipkowitz) and DK-52785 (R.G. Abramson) and a grant from the Dean, Mount Sinai School of Medicine (MSSM) (M.S. Lipkowitz and R.G. Abramson). Confocal laser scanning microscopy (CLSM) was performed at the MSSM-CLSM core facility, supported with funding from the NIH shared instrumentation grant (1 S10 RR0 9145) and National Science Foundation Major Research Instrumentation grant (DBI9724504). The authors express their appreciation to Zheng-Mei Liu for her excellent technical assistance.

1. Lehninger, A.L., Nelson, D.L., and Cox, M.M. 1993. Biosynthesis of amino acids, nucleotide, and related molecules. In Principles of biochemistry. A.L. Lehninger, editor. Worth Publishers. New York, New York, USA. 688-734.

2. Mahler, H.R. 1963. Uricase. In The enzymes. Volume 8. P.O. Boyer, H. Lardy, and K. Myrbäck, editors. Academic Press. New York, New York, USA. 285-296.

3. De Duve, C., and Baudhuin, P. 1966. Peroxisomes (microbodies and related particles). Physiol. Rev. 46:323-357.

4. Hruban, Z., and Recheigl, M. 1969. Microbodies and related particles. Morphology, biochemistry, and physiology. Int. Rev. Cytol. Suppl. 1:20-39.

5. Wu, X.W., Lee, C.C., Muzny, D.M., and Caskey, C.T. 1989. Urate oxidase: primary structure and evolutionary implications. Proc. Natl. Acad. Sci. USA. 86:9412-9416.

6. Wu, X.W., Muzny, D.M., Lee, C.C., and Caskey, C.T. 1992. Two independent mutational events in the loss of urate oxidase during hominoid evolution. J. Mol. Evol. 34:78-84.

7. Abramson, R.G., and Lipkowitz, M.S. 1990. Evolution of the uric acid transport mechanisms in vertebrate kidney. In Basic principles in transport. Volume 3. R.K.H. Kinne, editor. S. Karger AG. Basel, Switzerland. $115-153$.

8. Sorenson, L.B. 1960. The elimination of uric acid in man studied by means of $\mathrm{C}^{14}$-labeled uric acid. Uricolysis. Scand. J. Clin. Lab. Invest. 12(Suppl. 54):1-214.

9. Sorenson, L.B. 1978. Extrarenal disposal of uric acid. In Uric acid: handbook of experimental pharmacology. Volume 51. W.N. Kelley and I.M. Weiner, editors. Springer-Verlag. Berlin, Germany. 325-336.

10. Abramson, R.G., King, V.F., Reif, M.C., Leal-Pinto, E., and Baruch, S.B. 1982. Urate uptake in membrane vesicles of rat renal cortex: effect of copper. Am. J. Physiol. 242:F158-F170.

11. Abramson, R.G., and Lipkowitz, M.S. 1985. Carrier-mediated concentrative urate transport in rat renal membrane vesicles. Am. J. Physiol. 248:F574-F584

12. Knorr, B.A., Beck, J.C., and Abramson, R.G. 1994. Classical and channellike urate transporters in rabbit renal brush border membranes. Kidney Int. 45:727-736.

13. Roch-Ramel, F., Werner, D., and Guisan, B. 1994. Urate transport in brush-border membrane of human kidney. Am. J. Physiol. 266:F797-F805.

14. Blomstedt, J.W., and Aronson, P.S. 1980. $\mathrm{pH}$ gradient-stimulated transport of urate and p-aminohippurate in dog renal microvillus membrane vesicles. J. Clin. Invest. 65:931-934.

15. Guggino, S.E., Martin, G.J., and Aronson, P.S. 1983. Specificity and modes of the anion exchanger in dog renal microvillus membranes. Am. J. Physiol. 244:F612-F621.

16. Kahn, A.M., and Aronson, P.S. 1983. Urate transport via anion exchange in dog renal microvillus membrane vesicles. Am. J. Physiol. 244:F56-F63.

17. Kahn, A.M., Branham, S., and Weinman, E.J. 1983. Mechanism of urate and $\mathrm{p}$-aminohippurate transport in rat renal microvillus membrane vesi- 
cles. Am. J. Physiol. 245:F151-F158

18. Guggino, S.E., and Aronson, P.S. 1985. Paradoxical effects of pyrazinoate and nicotinate on urate transport in dog renal microvillus membranes. J. Clin. Invest. 76:543-547.

19. Kahn, A.M., Shelat, H., and Weinman, E.J. 1985. Urate and p-aminohippurate transport in rat renal basolateral vesicles. Am. J. Physiol. 249:F654-F661.

20. Leal-Pinto, E., et al. 1997. Molecular cloning and functional reconstitution of a urate transporter/channel. J. Biol. Chem. 272:617-625.

21. Leal-Pinto, E., Cohen, B.E., and Abramson, R.G. 1999. Functional analysis and molecular modeling of a cloned urate transporter/channel. $J$. Membr. Biol. 169:13-27.

22. Wada, J., and Kanwar, Y.S. 1997. Identification and characterization of galectin-9, a novel beta-galactoside-binding mammalian lectin. J. Biol. Chem. 272:6078-6086.

23. Wada, J., Ota, K., Kumar, A., Wallner, E.I., and Kanwar, Y.S. 1997. Developmental regulation, expression, and apoptotic potential of galectin-9, a beta-galactoside binding lectin. J. Clin. Invest. 99:2452-2461.

24. Tureci, O., Schmitt, H., Fadle, N., Pfreundschuh, M., and Sahin, U. 1997. Molecular definition of a novel human galectin which is immunogenic in patients with Hodgkin's disease. J. Biol. Chem. 272:6416-6422.

25. Matsumoto, R., et al. 1998. Human ecalectin, a variant of human galectin9 , is a novel eosinophil chemoattractant produced by T lymphocytes. $J$. Biol. Chem. 273:16976-16984.

26. Matsushita, N., et al. 2000. Requirement of divalent galactoside-binding activity of ecalectin/galectin-9 for eosinophil chemoattraction. J. Biol. Chem. 275:8355-8360.

27. Albrandt, K., Orida, N.K., and Liu, F.T. 1987. An IgE-binding protein with a distinctive repetitive sequence and homology with an IgG receptor. Proc. Natl. Acad. Sci. USA. 84:6859-6863.

28. Clerch, L.B., et al. 1988. Sequence of a full-length cDNA for rat lung betagalactoside-binding protein: primary and secondary structure of the lectin. Biochemistry. 27:692-699.

29. Gitt, M.A., Massa, S.M., Leffler, H., and Barondes, S.H. 1992. Isolation and expression of a gene encoding L-14-II, a new human soluble lactosebinding lectin. J. Biol. Chem. 267:10601-10606.

30. Oda, Y., et al. 1993. Soluble lactose-binding lectin from rat intestine with two different carbohydrate-binding domains in the same peptide chain. J. Biol. Chem. 268:5929-5939.

31. Barondes, S.H., Cooper, D.N., Gitt, M.A., and Leffler, H. 1994. Galectins. Structure and function of a large family of animal lectins. J. Biol. Chem. 269:20807-20810.

32. Gitt, M.A., et al. 1995. Sequence and mapping of galectin-5, a beta-galactoside-binding lectin, found in rat erythrocytes. J. Biol. Chem. 270:5032-5038.

33. Hadari, Y.R., et al. 1995. Galectin-8. A new rat lectin, related to galectin4. J. Biol. Chem. 270:3447-3453.

34. Madsen, P., et al. 1995. Cloning, expression, and chromosome mapping of human galectin-7. J. Biol. Chem. 270:5823-5829.

35. Gitt, M.A., et al. 1998. Galectin-4 and galectin-6 are two closely related lectins expressed in mouse gastrointestinal tract. J. Biol. Chem. 273:2954-2960.

36. Holzinger, A., Phillips, K.S., and Weaver, T.E. 1996. Single-step purification/solubilization of recombinant proteins: application to surfactant protein B. Biotechniques. 20:804-808.

37. Knorr, B.A., Lipkowitz, M.S., Potter, B.J., Masur, S.K., and Abramson, R.G. 1994. Isolation and immunolocalization of a rat renal cortical membrane urate transporter. J. Biol. Chem. 269:6759-6764.

38. Gottardi, C.J., Dunbar, L.A., and Caplan, M.J. 1995. Biotinylation and assessment of membrane polarity: caveats and methodological concerns. Am. J. Physiol. 268:F285-F295.

39. Najfeld, V., et al. 1992. Two diverged human homeobox genes involved in the differentiation of human hematopoietic progenitors map to chromosome 1, bands q41-42.1. Genes Chromosomes Cancer. 5:343-347.

40. Roush, D.L., Gottardi, C.J., Naim, H.Y., Roth, M.G., and Caplan, M.J. 1998. Tyrosine-based membrane protein sorting signals are differentially interpreted by polarized Madin-Darby canine kidney and LLC-PK1 epithelial cells. J. Biol. Chem. 273:26862-26869.

41. Sargiacomo, M., Lisanti, M., Graeve, L., Le Bivic, A., and RodriguezBoulan, E. 1989. Integral and peripheral protein composition of the apical and basolateral membrane domains in MDCK cells. J. Membr. Biol. 107:277-286.
42. Rappoport, J.Z., Lipkowitz, M.S., and Abramson, R.G. 1999. Cellular localization and topology of a urate transporter/channel in mammalian cells. J. Am. Soc. Nephrol. 10:57a. (Abstr.)

43. Barondes, S.H., et al. 1994. Galectins: a family of animal beta-galactosidebinding lectins. Cell. 76:597-598.

44. Hughes, R.C. 1999. Secretion of the galectin family of mammalian carbohydrate-binding proteins. Biochim. Biophys. Acta. 1473:172-185.

45. Gutman, A.B., and Yu, T.-F. 1957. Renal function in gout. With a commentary on the renal regulation of urate excretion, and the role of the kidney in the pathogenesis of gout. Am. J. Med. 23:600-622.

46. Steele, T.H. 1978. Urate excretion in man, normal and gouty. In Handbook of experimental pharmacology. Volume 51. W.N. Kelley and I.M. Weiner, editors. Springer-Verlag. Berlin, Germany. 257-286.

47. Saggiani, F., et al. 1996. Serum uric acid and related factors in 500 hospitalized subjects. Metabolism. 45:1557-1561.

48. Jossa, F., et al. 1994. Serum uric acid and hypertension: the Olivetti heart study. J. Hum. Hypertens. 8:677-681.

49. Goldstein, H.S., and Manowitz, P. 1993. Relation between serum uric acid and blood pressure in adolescents. Ann. Hum. Biol. 20:423-431.

50. Mazzali, M., et al. 2000. Hyperuricemia causes hypertension and renal disease via a novel crystal-independent mechanism. J. Am. Soc. Nephrol. 11:337a. (Abstr.)

51. Moro, F., et al. 1991. Familial juvenile gouty nephropathy with renal urate hypoexcretion preceding renal disease. Clin. Nephrol. 35:263-269.

52. McBride, M.B., et al. 1991. Renal urate hypoexcretion preceding renal disease in a new kindred with familial juvenile gouty nephropathy (FJGN). Adv. Exp. Med. Biol: 309A:191-194.

53. Yokota, N., et al. 1991. Autosomal dominant transmission of gouty arthritis with renal disease in a large Japanese family. Ann. Rheum. Dis. 50:108-111.

54. Saeki, A., et al. 1995. Newly discovered familial juvenile gouty nephropathy in a Japanese family. Nephron. 70:359-366.

55. McBride, M.B., et al. 1998. Presymptomatic detection of familial juvenile hyperuricaemic nephropathy in children. Pediatr. Nephrol. 12:357-364.

56. Massari, P.U., et al. 1980. Familial hyperuricemia and renal disease. Arch. Intern. Med. 140:680-684.

57. Puig, J.G., et al. 1993. Hereditary nephropathy associated with hyperuricemia and gout. Arch. Intern. Med. 153:357-365.

58. Reiter, L., Brown, M.A., and Edmonds, J. 1995. Familial hyperuricemic nephropathy. Am. J. Kidney Dis. 25:235-241.

59. Leumann, E.P., and Wegmann, W. 1983. Familial nephropathy with hyperuricemia and gout. Nephron. 34:51-57.

60. Syrjanen, J., Mustonen, J., and Pasternack, A. 2000. Hypertriglyceridaemia and hyperuricaemia are risk factors for progression of IgA nephropathy. Nephrol. Dial. Transplant. 15:34-42.

61. Langford, H.G., et al. 1987. Is thiazide-produced uric acid elevation harmful? Analysis of data from the Hypertension Detection and Follow-up Program. Arch. Intern. Med. 147:645-649.

62. Bengtsson, C., Lapidus, L., Stendahl, C., and Waldenstrom, J. 1988. Hyperuricaemia and risk of cardiovascular disease and overall death. A 12-year follow-up of participants in the population study of women in Gothenburg, Sweden. Acta Med. Scand. 224:549-555.

63. Freedman, D.S., Williamson, D.F., Gunter, E.W., and Byers, T. 1995. Relation of serum uric acid to mortality and ischemic heart disease. The NHANES I Epidemiologic Follow-up Study. Am. J. Epidemiol. 141:637-644.

64. Alderman, M.H., Cohen, H., Madhavan, S., and Kivlighn, S. 1999. Serum uric acid and cardiovascular events in successfully treated hypertensive patients. Hypertension. 34:144-150.

65. Johnson, R.J., Kivlighn, S.D., Kim, Y.G., Suga, S., and Fogo, A.B. 1999. Reappraisal of the pathogenesis and consequences of hyperuricemia in hypertension, cardiovascular disease, and renal disease. Am. J. Kidney Dis. 33:225-234.

66. Culleton, B.F., Larson, M.G., Kannel, W.B., and Levy, D. 1999. Serum uric acid and risk for cardiovascular disease and death: the Framingham Heart Study. Ann. Intern. Med. 131:7-13.

67. Dobson, A. 1999. Is raised serum uric acid a cause of cardiovascular disease or death? Lancet. 354:1578.

68. Johnson, R.J., Tuttle, K.R., Culleton, B., and Levy, D. 2000. Much ado about nothing, or much to do about something? The continuing controversy over the role of uric acid in cardiovascular disease. Hypertension. 35:E10-E12. 